and shipping were not available, and they could not be recouped in goods and services." 19

\section{IV}

$\mathrm{Six}^{20}$ of Dutta's eight estimates are for imports by categories, viz., consumer goods $\left(m_{c}\right)$, intermediate goods $\left(m_{i n t}\right)$, and investment goods $\left(m_{i}\right)$. Of these, three numbers (3), (6), and (7), may be ignored since standard errors of at least one of the parameters in each of these three are unacceptably high. Of the remaining three, number (4) is open to several objections: this is

$$
\begin{aligned}
m_{c} / N & =1.56-0.03 t+0.16\left(X / P_{m}\right) / N \\
& +0.37\left(m_{c} / N\right)_{-1}
\end{aligned}
$$

where $N$ denotes total population. Firstly, if $X / P_{m}$ is interpreted as the financial constraint to the propensity to import, then the use of $\left(X / P_{m}\right) / N$ does not make sense: The authorities cannot be assumed to be concerned with population changes in balancing foreign accounts. Secondly, even if the latter objection is invalid, the population variable has been used in a manner which makes it superfluous: Conceptually, there is no difference between

$$
m_{c}=A+B(\text { trend })+C\left(X / P_{m}\right)+D\left(m_{c}\right)_{-1}
$$
and

$$
\begin{aligned}
m_{c} / N & =A+B(\text { trend })+C\left(X / P_{m}\right) / N \\
& +D\left(m_{c} / N\right)_{-1} .
\end{aligned}
$$

And even statistically, the respective elasticities were found to be similar. Thirdly, the explanatory variables are highly correlated, two of them being as high as 0.82 and 0.76 . The explanatory variables of equations (5) and (8) are also highly correlated. Last but not least, the use of manifestly nonhomogeneous sample casts doubts over the statistical results obtained.

\section{$\mathrm{V}$}

Reestimates of Dutta's equations (1) to (8), using his own data for $1920-1938,{ }^{21}$ produced the following results:

\footnotetext{
${ }^{19}$ Shannon, ibid., p. 540.

${ }^{20}$ That is, two for $m_{c}$, one for $m_{i n t}$, and three for $m_{i}$.

${ }^{21}$ The year immediately following the 1914-1918 war
}

$$
\begin{aligned}
& m=-43.10+.41 t+.0004\left(X / P_{m}\right)+177.51 P \\
& 68.40 \quad .79 \quad .13 \\
& \bar{R}^{2} .42 \\
& m^{\prime}=-53.12-.11 t-.001\left(X^{\prime} / P_{m}\right) \\
& \begin{array}{lll}
69.18 \quad .86 \quad .13
\end{array} \\
& +195.00\left(P_{h} / P_{m}\right) \\
& 75.61 \\
& m_{c} / N=.24-.34(A / N)+.63\left(m_{c} / N\right)_{-1} \bar{R}^{2} .49 \quad(2 \mathrm{a})^{22} \\
& m_{c} / N=.17-.005 t+.14\left(X / P_{m}\right) / N \\
& +.22\left(m_{c} / N\right)_{-1} \\
& .23 \\
& \bar{R}^{2} .45 \\
& m_{\text {int }}=-18.38+.07 t+.37 I \text { (ours) } \\
& 9.15 \quad .51 \quad .15 \\
& +17.47 P_{i n t}+.14 m_{\text {int }-1} \\
& 6.99 \quad .18 \\
& \bar{R}^{2} .82 \\
& m_{i}=\begin{array}{c}
-1.31-2.43 t \\
22.17 \\
.82
\end{array} . .82 I \text { (Mukherji) } \\
& +.48 m_{i-1} \\
& .14
\end{aligned}
$$

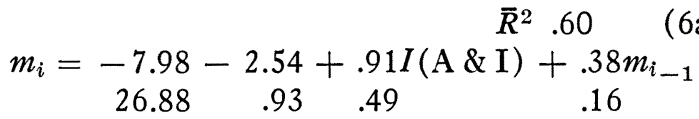

$$
\begin{aligned}
& m_{i}=19.54-2.12 t+.44 I(\text { Meek })+.58 m_{i_{-1}} \\
& \begin{array}{llll}
20.55 & 1.16 & .41 & .15
\end{array} \\
& \bar{R}^{2} .53
\end{aligned}
$$

Clearly, Dutta's import equations are not statistically significant ${ }^{23}$ when the sample data used is a little more acceptable.

has been omitted to allow for at least some of the adjustments necessary after the upheavals in the national and international economy.

${ }^{22}$ For "British India" inclusive of Burma, i.e., for 19201936.

${ }^{23}$ Estimates (6a) and (7a) come very near to being acceptable; but these happen to be those equations, which, in Dutta's estimate, are not significant statistically.

\title{
THE ROLE OF SAVING IN A GROWTH MODEL WITH INDUCED INVENTIONS: A CORRECTION
}

\author{
Edwin Burmeister, Winston W. Chang and Rodney Dobell
}

In a recent article [2] in this Review written by one of the present authors, it is asserted that when $\sigma<1$ and $s_{1}>s_{2}>0$, the steady-state growth equilibrium with a positive rate of growth of capital is stable for most of the initial conditions; however, there may exist a region in which capital's share is sufficiently high and the rate of growth of capital is sufficiently low such that a path starting from 
any point in this region will converge to a quasiequilibrium state with a zero rate of growth of capital [2, p. 66]. The present note indicates that the steady-state growth equilibrium with a positive rate of growth of capital in this case is, in fact, globally stable.

The erroneous result in [2] comes from the assertion that $\hat{K}(0) \geqq 0$ implies $\hat{K}(t) \geqq 0$ for all $t$ (p. 65). Instead this assertion should be stated as (i) $\hat{K}(0)=0$ implies $\hat{K}(t)=0$ for all $t$, and (ii) $\hat{K}(0)>0$ implies $\hat{K}(t)>0$ for all $t$. The former follows from equation (11) in [2] and the latter from uniqueness and continuity (with respect to the initial conditions) of the solution paths. Thus, in view of equation (10) in [2], $\hat{K}(t)>0$ may converge to zero only asymptotically. It follows that a path starting from any initial state with $\infty>\hat{K}(0)>0$ and $0<a(0)<1$ (like the path starting from point $P$ in figure 2 of [2]) will not hit the horizontal axis and will eventually converge to point $E$. Thus the steady-state growth equilibrium in this case is globally stable.

It is cumbersome to work with the $(a, \hat{K})$ space used in [2]. The analysis of the dynamic behavior of the model can be greatly simplified if one uses the $(a, Y / K)$ space. This has been done in chapter 3 of the Burmeister-Dobell book [1]. It is shown there that the dynamic behavior of the model in which $s_{1}>s_{2}>0$ does not differ qualitatively from the one in which $s_{1}=s_{2}[1$, p. 89]. (See also Exercise 15, (p. 99) and Hint 15 (pp. 102-103).) Thus the same results are obtained, although the phase spaces used are different.

\section{REFERENCES}

[1] Burmeister, E., and R. Dobell, Mathematical Theories of Economic Growth (New York: Macmillan Company, 1970).

[2] Chang, W. W., "The Role of Saving in a Growth Model with Induced Inventions," this REVIEw, LII (Feb. 1970), 62-67.

\title{
WORK INCENTIVES OF THE POOR: A RECONSIDERATION
}

\author{
Ronald F. Hoffman and Bradley R. Schiller*
}

In a recent article Green and Tella attempted to illustrate and measure the alleged negative impact of income supplement programs on the labor supply of the poor. ${ }^{1}$ Using cross-sectional data on the incomes and labor force participation of low-income families, the authors claim to have demonstrated that more nonemployment income leads to less labor supply, given constant employment opportunities. On the basis of this demonstration and an examination of attendant wage rate variations, Green and Tella conclude that negative income tax programs will lead to a reduced labor supply on the part of the poor and a consequent reduction in GNP of at least $\$ 1$ billion. In the following discussion we will argue that the data and assumptions employed by Green and Tella were not adapted to the problem they wished to solve, and that the methodology they utilized not only biased their results but also incorporated serious conceptual errors.

The data basis for the Green and Tella arguments consists of the following information:

$Y=$ total family income, where income levels are known only to the nearest $\$ 1,000$;

* Division of Economic and Long-Range Studies, Office of Research and Statistics, Social Security Administration, Department of Health, Education, and Welfare, Washington, D.C.

${ }^{1}$ Green, Christopher and Tella, Alfred, "Effect of Nonemployment Income and Wage Rates on the Work Incentives of the Poor," this Review (Nov. 1969), pp. 399-408.
$N=$ amount of nonemployment income received; and

$F=$ a classificatory variable which indicates whether or not the respondent worked fulltime on a year-round basis.

From these data the authors proceed to estimate:

$W=$ wage income, obtained as $Y-N$;

$H=$ hours worked, which is an estimate of annual hours worked by full-time and parttime (or part-year) workers respectively; and

$w=$ wage rates, calculated as $W \div H$.

Observing that those respondents within any given income bracket (e.g., $\$ 2,000-\$ 3,000$ ) who have no nonemployment income are more likely to be fulltime workers than those who do, the authors set out to demonstrate that the receipt of nonemployment incomes imposes negative income effects on the labor supply of the poor population. Green and Tella also attempt to approximate a situation where wage rates vary so that the substitution effects of a negative income tax can be measured. In the remainder of their paper they attempt to isolate and quantify these alleged negative responses.

It should be noted at the outset that the imputation of negative labor supply responses to the receipt of nonemployment income $(N)$ presupposes that the recipients of $N$ confront the same employ- 